\title{
aniki
}

Revista Portuguesa da Imagem em Movimento

Portuguese Journal of the Moving Image

\section{DOC'S KINGDOM 2013: Resistência de uma ilha} Pablo Cayuela ${ }^{1}$

Doc's Kingdom 2013: Ideia de uma Ilha. Seminário Internacional sobre Cinema Documental (Faial, Pico - Açores, Portugal), 15-20 de setembro de 2013.
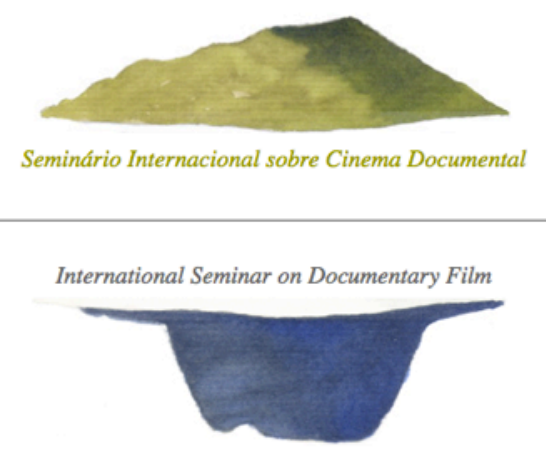

Imagem 1: Doc's Kingdom : Ideia de uma ilha | ๔ Ana Eliseu / Doc's Kingdom

Entre os anos 2000 e 2010, o Doc's Kingdom foi-se tornando, discretamente, num dos encontros de referência para o estudo e o debate em torno do cinema contemporâneo. Com um rigor e uma autoconsciência pouco característicos da maioria dos eventos dedicados à exibição cinematográfica, os organizadores souberam determinar com precisão as linhas de orientação que viriam a definir o encontro e, sobretudo, decidir o que este não deveria ser. Dessa forma, e tendo o Flaherty Film Seminar como referência e contando com o apoio da Apordoc (Associação pelo Documentário, que incentiva também o Doclisboa), o Doc's Kingdom transformou-se num seminário internacional, pequeno por vocação, oposto à tendência acumulativa e mercantilista do formato "festival" e celebrado durante os seus primeiros dez anos de existência na pequena localidade de Serpa, no Alentejo português.

Durante esta primeira etapa, a equipa dirigida por José Manuel Costa estabeleceu as suas normas de funcionamento, baseadas na programação de um número reduzido de filmes (desde 6 em 2001, a 33 em 2008), concentrados em sessões intensivas e sem que projeções simultâneas pudessem impedir os participantes de ver e partilhar exatamente os mesmos filmes. Este método reforça outro dos pilares sobre os quais repousa o projeto do Doc's Kingdom: a rea-

\footnotetext{
${ }^{1}$ Crítico de cinema freelance.
} 
lização de debates diários entre o público (estudantes, realizadores, programadores ou a própria equipa de produção), cuja intensidade e eficácia dependem, antes de mais, da aposta num programa único e comum a todos os participantes. Um conjunto de filmes oscilando entre estreias mundiais, raridades restauradas ou clássicos contrapostos, mas sempre conscientemente reunidos para além de classificações redutoras que pretendam determinar de antemão os limites do cinema documental. Em vez disso, o programa articula-se a partir de uma epígrafe orientadora (associada ao título do seminário durante as últimas edições: a imagem-arquivo, paisagem / tempo, a circulação da palavra...), em torno da qual gravita, com uma flexibilidade notável, toda a seleção de filmes.

\section{Faial-Pico $^{2}$}

Depois de dois anos de interrupção por falta de financiamento, o Doc's Kingdom reapareceu em 2013 com uma novidade principal: a sua mudança para o arquipélago dos Açores (Portugal). É provável que a busca de apoios económicos e patrocínios tenha determinado o novo lugar do encontro, mas a direção do seminário (a quem se juntou, nesta edição, Nuno Lisboa, até então programador) quis aproveitar a oportunidade para internacionalizar o evento ${ }^{3}$ e, inclusive, propor uma programação que evocava a condição insular através do rótulo sugestivo de Ideia de uma ilha, alusão explícita ao filme homónimo de Roberto Rossellini (Idea di un'isola, 1968).

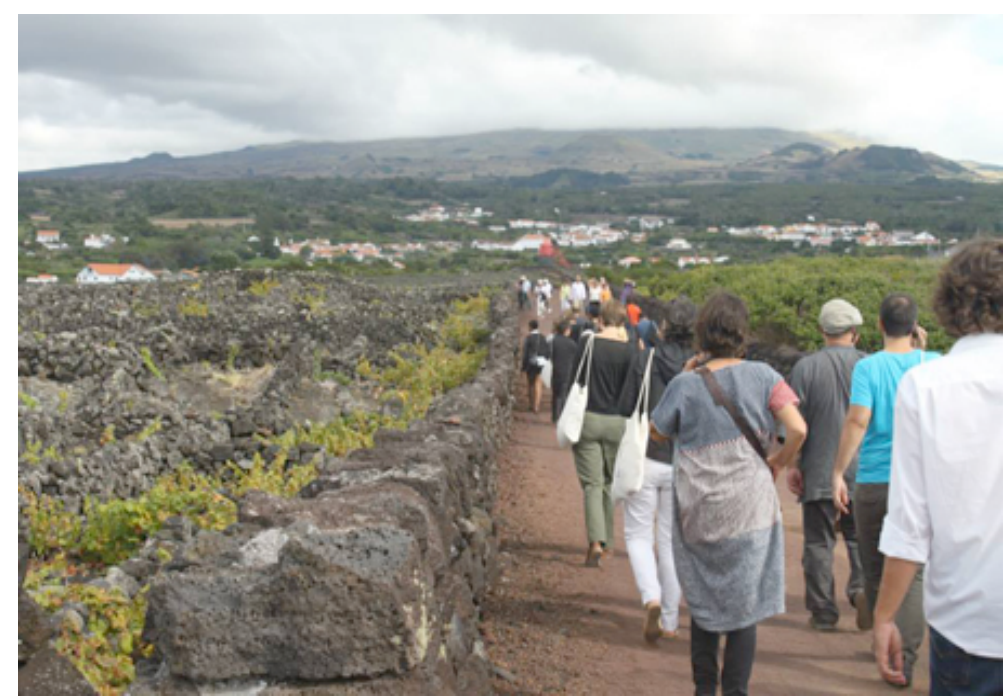

Imagem 2: Doc's Kingdom 2013 | (C) Doc's Kingdom.

\footnotetext{
2 "Em 2013 o lugar do seminário é a ilha do Faial, e, de um outro modo, o binómio Faial-Pico, dois lugares que podem ser considerados como um, apetecendo aliás dizer que um deles (o Pico) é também parte do outro, enquanto horizonte do olhar, visão permanente e objecto mutante (dir-se-ia cinematográfico)." http://www.docskingdom.org/pt/entrada.html.

${ }^{3}$ Por exemplo, ao colaborar com a CalArts (California Institute of the Arts), que atribuiu bolsas a quase uma dezena dos seus alunos para assistirem ao seminário.
} 
A transferência para as ilhas apresentava uma série de inconvenientes, quase todos relacionados com a necessidade de garantir a presença no seminário de estudantes ou trabalhadores precários, que até então constituíam uma elevada percentagem dos inscritos. Se realçamos este aspeto, é apenas para elogiar a política de bolsas ${ }^{4}$ e o esforço da equipa de produção, em particular de Maria João Soares e Inês Mestre, em propor pacotes de inscrição acessíveis, revelando a atenção da organização ao atual contexto de espoliação económica. Mais uma vez, o que se pode elogiar é o funcionamento do Doc's Kingdom e o modo como reflete constantemente sobre a sua existência num "aqui" e num "agora".

Um aqui, o das ilhas açorianas, que atravessou sempre a programação sob a forma de uma metonímia cingelada a todas as propostas - gráficas, cinematográficas ou escritas - que deram forma ao seminário: "um programa de visões utópicas e distópicas do mundo em que vivemos: lugares insulados onde se condensa o mundo inteiro, territórios descobertos onde se sobrepõem, como numa rocha estratificada, diferentes tempos e origens, gestos solitários e gestus coletivos, tensões entre o visível e o invisível, a palavra e a imagem, o interior e o exterior, o real e o imaginário, a memória e a transformação" 5 .

Se esta série de oposições parece adaptar-se a qualquer filme documental, os vinte títulos projetados no Teatro Faialense - que, pela primeira vez nesta edição, não tinham sido divulgados previamente - cumpriram a sua função ao alargar e desenvolver esta ideia central. A predominância dos modelos do cinema etnográfico na seleção de filmes não foi certamente um acaso, dada a sua apetência histórica por comunidades isoladas onde se condensa o mundo inteiro, ou ainda devido às diferentes aceções da utopia que a etnografia manuseou durante um século e meio. Entre a insularidade sublimada do Homem de Aran de Robert Flaherty (1933) e o oceano capitalista de Allan Sekula e de Noël Burch em The Forgotten Space (2012) - as duas únicas sessões da semana abertas ao público local - , ficaram definidos os marcos entre os quais se moveu um programa em busca permanente de ligações e de concordâncias inesperadas.

Um bom exemplo disto foi o dia em que o alinhamento juntou Beschreibung einer Insel (Estudo de uma ilha, Cynthia Beatt e Rudolf Thome, 1979) com o recente vencedor da secção "Cineasta do presente" do festival de Locarno, Manakamana (Stephanie Spray e Pacho Velez, 2013). Duas propostas radicais e controversas que, apesar das suas disparidades formais e temáticas, deram origem a um

\footnotetext{
${ }^{4}$ Pablo Cayuela foi um dos beneficiários das bolsas do Doc's Kingdom (nota do editor).

5 "Ideia de uma ilha", http://www.docskingdom.org/pt/entrada.html (consultado em 26 de dezembro 2013)
} 
debate animado sobre a prática etnográfica e o artifício cinematográfico. Assinale-se apenas, e por agora, que a maioria das intervenções que criticaram o formalismo rígido de Manakamana utilizaram o contra-campo representado ${ }^{6}$ na película de Beatt e Thome como argumento, como se os mais de trinta anos que separam cada proposta não tivessem sido capazes de atenuar a suspeita em torno do pacto entre o cineasta e o sujeito filmado.

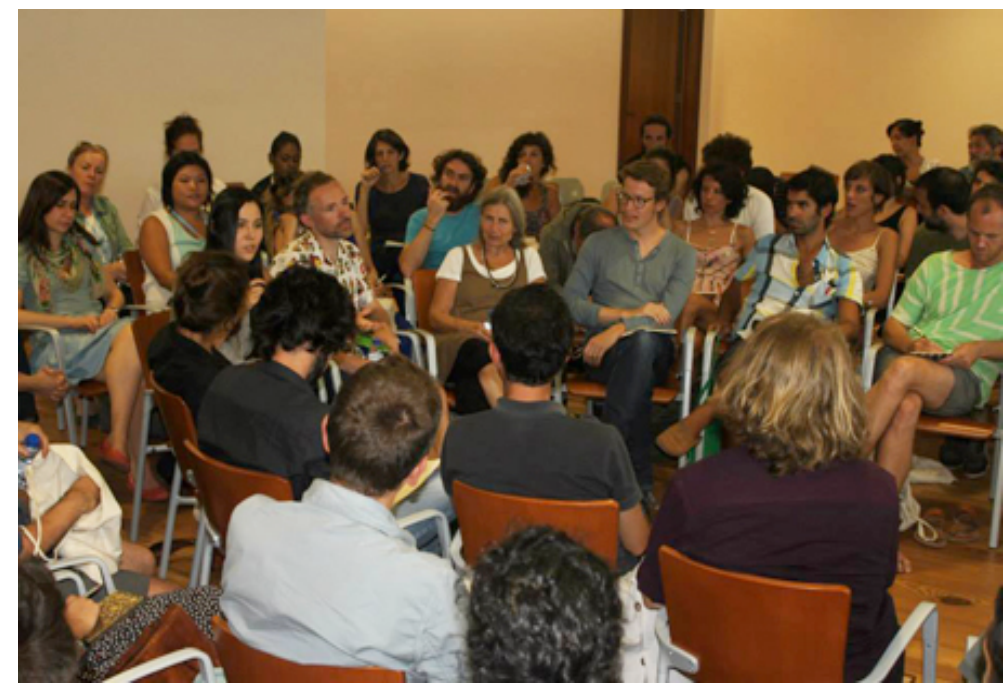

Imagem 3: Doc's Kingdom 2013 | ㄷ Doc's Kingdom.

Sendo assim, nada melhor do que a brilhante auto-etnografia de Kidlat Tahimik em Mababangong bangungot (1977) para escapar ao atoleiro eurocêntrico, através do relato na primeira pessoa de um jovem filipino, interpretado pelo próprio cineasta, que sonha viajar para a Europa e os Estados Unidos para participar na corrida espacial. Tahimik utiliza todas as ferramentas ao seu alcance - desde a estratégia documental puramente observacional ou o diário filmado até aos rudimentos do film noir ou da série B - para elaborar uma crítica divertida e incisiva da ocupação colonial, que ganha em profundidade em função da liberdade com a qual o jovem cineasta filma e monta o seu filme.

Algures num meio termo, as utopias ruralistas de João Vladimiro (Lacrau, 2013) e de Eloy Enciso (Arraianos, 2012), talvez demasiado desproblematizadas, cruzaram-se com o espiritualismo experimental dos dois Bens em A Spell to Ward off the Darkness (Ben Rivers e Ben Russell, 2013), The Creation as We Saw It (Ben Rivers, 2012) e Let Us Persevere in What We Have Resolved before We Forget

\footnotetext{
${ }^{6}$ Beschreibung einer Insel, na esteira das novas políticas do outro formuladas nos anos 60 e 70, regista e subjetiviza o trabalho de campo de um grupo de antropólogos que estuda uma comunidade do sudeste do oceano Pacífico, através da incorporação de inúmeros elementos ficcionais que recordam a encenação de La Pyramide Humaine (Jean Rouch, 1961).
} 
(Ben Russell, 2013), tendo estes dois últimos filmes sido filmados separadamente num mesmo local, o arquipélago de Vanuatu, na Melanésia.

Ainda houve tempo para integrar outras ilhas no mapa desenhado pelo Doc's Kingdom, na forma de intensos relatos pessoais, simbolizados, de uma forma ou de outra, pela casa de banho de Berlim 10/90 (1991), a partir da qual Robert Kramer deu voz (e silêncio) aos infortúnios da Europa pós-soviética, num singularíssimo gesto cinematográfico que faz confluir a História no corpo vencido do cineasta. Que este tenha sido o filme escolhido para inaugurar a presente edição do Doc's Kingdom não foi certamente um acaso, uma vez que o seminário se inspira, mais do que no título de um filme, num autor fortemente vinculado a Portugal e à sua fase pósrevolucionária ${ }^{7}$.

Outro corpo atravessado pela doença, o de Joaquim Pinto, é o motivo a partir do qual se organiza a narrativa autobiográfica de $E$ agora? Lembra-me (2013). O antigo amigo e colaborador de Kramer, sofrendo de SIDA e de hepatite C, dedica-se a um diário pessoal que dá conta dum ano de tratamento com medicamentos experimentais destinadas a travar o avanço de ambos os vírus. O vitalismo profuso do seu acabamento digital, pontuado pelas reflexões de Joaquim e do seu companheiro, Nuno, abrem o filme a territórios mais vastos, onde o amor e a política se cruzam, num derradeiro e magnífico gesto que nos recorda Berlim 10/90.

Por seu lado, Nicolas Rey viaja até ao coração do gulag a pretexto de uma canção de Vysotky, Magadan, que desde o começo do filme dá o tom casual, leve e, por vezes, humorístico, que atravessa Les soviets plus l'éléctricité ("O comunismo são os Sovietes mais a eletricidade”, terá dito Lenine). A bússola super-8 de Rey é parca em imagens e sons, ou o inverso, se levarmos em linha de conta as numerosas sequências em ecrã negro e os intervalos silenciosos do gravador onde o cineasta aponta as suas impressões. A materialidade destes silêncios sonoros e visuais ${ }^{8}$ é tão forte que voltamos a pensar (porque assim nos permite a programação) no eco estrondoso da sala de banho onde Kramer permanece mudo.

\footnotetext{
${ }^{7}$ Doc's Kingdom (Robert Kramer, 1987) é o segundo filme de Kramer protagonizado por Doc, uma espécie de alter-ego do cineasta, criado para a realização de Ice (1969). Posteriormente, Kramer recuperará esse mesmo personagem no seu filme Route One (1989).

8 “'O que prefiro aqui', diz Nicolas Rey na banda sonora, 'é o défice de informação'. Não fala naturalmente do que vê, destas paisagens infinitas da tundra, destas carcaças de navios e de camiões esquecidos à beira da estrada, destes veículos atolados. E porque é que nós, espectadores, nos sentimos atraídos por esse défice que ele nos transmite através da imagem cinematográfica?” Jean-Michel Bouhours, 2010, "Les Soviets plus l'électricité", Lumière, http://www.elumiere.net/especiales/nicolasrey/soviets_bouhours.php (acedido em 26 de dezembro de 2013).
} 
Não há aqui espaço para detalhar o resto dos filmes programados por José Manuel Costa, Nuno Lisboa e Federico Rossin (e excelentemente amparados por toda a equipa técnica), mas um dos objectivos prioritários do seminário é a publicação, em livro e na internet (www.docskingdom.org), dos sugestivos debates que acompanham e dão sentido a cada uma das suas edições, pelo que o leitor interessado poderá aprofundar devidamente algumas das questões aqui levantadas de forma necessariamente superficial, naquilo que será a descrição dessa ilha de resistência que é o Seminário Internacional sobre Cinema Documental Doc's Kingdom. 